\title{
FOREWORD
}

For reprint orders, please contact: reprints@futuremedicine.com

\section{Hepatic Oncology: a journal for all stakeholders in liver cancer management}

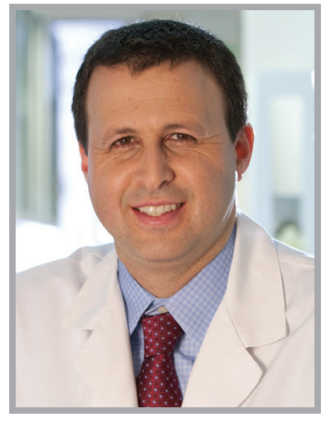

Richard S Finn*1

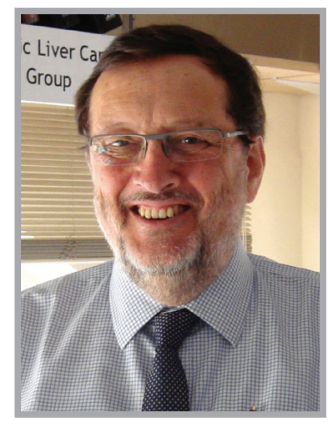

Jordi Bruix ${ }^{2}$
On behalf of the Editorial Board, we are excited to welcome you to the first edition of Hepatic Oncology, a multidisciplinary journal with a focus on liver malignancies. The past decade has brought a robust amount of interest in liver cancer, spanning from bench research to the clinic in all aspects of liver tumor management. Our goal in the development of the journal is to provide a high-impact outlet for basic science, as well as all clinical aspects of liver oncology. We are seeking to encourage submissions from all stakeholders in liver cancer, including laboratory scientists, hepatologists, gastroenterologists, surgeons, medical oncologists, radiologists and pathologists, among others. In addition, we hope to maintain a broad readership, not just focused on hepatocellular carcinoma, but cholangiocarcinoma and other liver tumors as well.

The first issue of the journal features a range of articles, including reviews, perspectives and editorials. A diverse spread of topics are discussed, from surgical treatment to molecular therapy. Hepatocellular carcinoma, cholangiocarcinoma and metastatic colorectal cancer to the liver all feature, and are discussed by a range of experts from North America, Europe and Asia. The inaugural issue also features an interview with a member of our Editorial Board, Dr Shahid Khan from Imperial College (London, UK), who discusses his work in hepatology and, in particular, his involvement in the creation of national guidelines for the management of cholangiocarcinoma.

Given the unique multidisciplinary characteristics of hepatic oncology, we feel that the field will greatly benefit from a journal focused in this area of investigation. We are committed to a rapid review time and a format where the latest science will be presented and reach those with a specific interest in the field.

Article proposals are welcomed by the editorial team, and we encourage you to submit your next liver cancer work to Hepatic Oncology.

Financial \& competing interests

disclosure

The authors have no relevant affliations or financial involvement with any organization or entity with a financial interest in or financial conflict with the subject matter or materials discussed in the manuscript. This includes employment, consultancies, honoraria, stock ownership or options, expert testimony, grants or patents received or pending, or royalties.

No writing assistance was utilized in the production of this manuscript.

'University of California, Los Angeles, Division of Hematology/Oncology, Los Angeles, CA 90095, USA

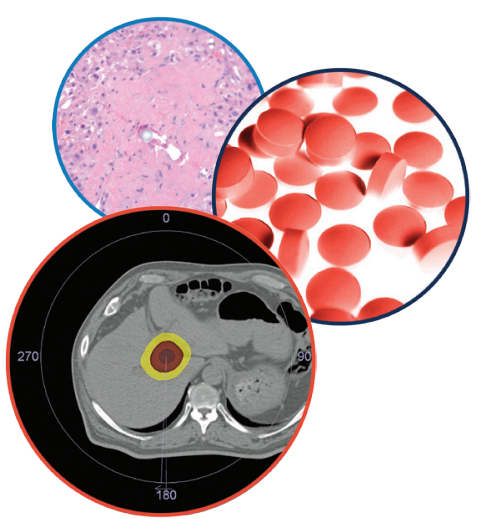

“...we hope to maintain a broad readership, not just focused on hepatocellular carcinoma, but cholangiocarcinoma and other liver tumors as well."

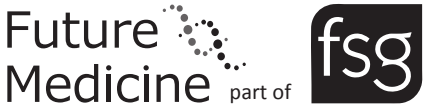

